\title{
Las diversas entonaciones de una sola voz. Historia, ciudadanía y nación en Carlos Monge Alfaro ${ }^{1}$
}

Patricia Alvarenga Venutolo ${ }^{2}$

Universidad Nacional, Costa Rica

resumen

Analiza la obra del historiador Carlos Monge Alfaro y explora sus diferentes narrativas de la construcción de la historia desde la perspectiva teórica y de la experiencia del mundo costarricense. Concibe a Monge Alfaro como un autor que ensaya visiones contrapuestas del universo social, y no como un intelectual coherente y aprehensible, constructor de ideas claramente hilvanadas en sus diferentes textos. Cuando Monge Alfaro deja de ser un intelectual de oposición para participar en la construcción de un proyecto hegemónico, reconstituye su discursividad inicial en respuesta a las transformaciones dadas en su concepción de la relación entre el mundo social y el poder.

\begin{abstract}
An analysis is presented of the work the historian Carlos Monge Alfaro and of the different ways that he narrates the construction of history from a theoretical perspective and the experience of the Costa Rican world. Monge Alfaro is conceived as an author who presents contradictory views of the social universe and not as a coherent and apprehensible intellectual, constructing ideas which are linked in his different texts. When Monge Alfaro stopped being an intellectual of the opposition to participate in the construction of a hegemonic project, he reconstructed his initial discourse as a response to the transformations present in his conception of the relation between the social world and power.
\end{abstract}

1 Ponencia presentada en el xx Congreso Internacional de Literatura Centroamericana (ciLca) 2012. Recibido: 30 de marzo de 2011; aceptado: 4 de agosto de 2011.

2 Correo electrónico: patriciaalvarengavenutolo@gmail.com

$$
L_{\text {etras }} 50 \text { (2011), ISSN 1409-424X }
$$


Palabras clave: ensayo costarricense, historiografía, historia de Costa Rica Keywords: Costa Rican essay, historiography, Costa Rican history

\section{Introducción}

Carlos Monge Alfaro es uno de los intelectuales del siglo xx que más influyó en la construcción de la sociedad costarricense. Entre sus obras está su Historia de Costa Rica, lectura obligatoria de generaciones de estudiantes de secundaria y terreno básico de discusión del mundo académico nacional ${ }^{3}$. En 1934, al concluir sus estudios en Instituto Pedagógico de Chile, regresa a Costa Rica para participar vigorosamente en la creación de una reinterpretación de la historia de del país así como en la constitución de un nuevo proyecto de sociedad ${ }^{4}$. Fue figura protagónica del «Centro de estudios para los problemas nacionales» constituido en 1939 bajo el liderazgo del intelectual Roberto Brenes Mesén. Isaac Felipe Azofeifa, Rodrigo Facio y Carlos Monge Alfaro se cuentan entre sus integrantes destacados. En 1944, el Centro establece una alianza con los partidarios de León Cortés, vencido mediante un proceso electoral cuestionable, por el oficialista, Teodoro Picado. Al año siguiente, Surco anuncia la integración del Centro en una nueva agrupación política: el Partido Social Demócrata. En éste, junto con los cortesistas, los centristas pasaron del análisis de la política a la acción con miras a la toma del poder ${ }^{5}$. No lo obtendrán por la vía de las urnas; en las siguientes elecciones presidenciales un descontento generalizado por la confusión en los resultados electorales los llevó a participar en la Revolución del 48.

En la década de 1940 Monge Alfaro, desde las páginas de Sur$c o$, desarrolla una reflexión de la sociedad costarricense que tiene

3 Iván Molina Jiménez, «Carlos Monge Alfaro y la democracia rural» en Carlos Monge Alfaro, Conceptos sobre la evolución de Costa Rica en el siglo XVIII (San José: EUNED, 2007) vii-xx.

4 Juan Rafael Quesada, Carlos Meléndez, Isaac Felipe Azofeifa y Eduardo Fournier, Carlos Monge Alfaro (San José: Editorial de la Universidad de Costa Rica, 1988) 72-84.

5 Con la formación del Partido Social Demócrata, Surco se fusiona con el periódico «Acción Demócrata» dando origen al nuevo periódico Social Demócrata. Jorge Romero P., La socialdemocracia en Costa Rica (San José: Talleres Gráficos de Trejos Hermanos, 1977) 116. 
como eje la historia y como punto de llegada, la construcción ciudadana. Para él la historia visibiliza la problemática del presente en aras de trazar las rutas óptimas hacia el futuro. Pero su concepción histórica no se centra, como lo hicieron sus predecesores, en las glorias de la patria o en la edificación de los hombres que en el pasado tuvieron en sus manos la dirección del país. Dos escenarios contribuyen a delinear la dirección de su escritura. El nazismo le preocupa por cuanto la política en un país representativo del mundo del progreso ha conducido a la brutal deshumanización expresada con particular crudeza en los campos de exterminio ${ }^{6}$. Pero el escenario más significativo para Monge Alfaro es el local. Surco es la voz de una generación de excelsos intelectuales que reunidos en el «Centro para el estudio de los problemas nacionales» tienen como metas crear una oposición para renovar la política y acabar con lo que denominaron 《viciadas prácticas politiqueras» ${ }^{7} \mathrm{y}$ diseñar nuevas estrategias económicas y sociales, destinadas al progreso y al bienestar.

Monge Alfaro intenta construir un proyecto alternativo que trascienda la mera sustitución del gobierno de turno. Éste, se presenta como un nuevo proyecto de país, de nación. Aquí vamos a analizar cómo crea su propuesta de transformación de la vida política a partir del análisis histórico y mediante la constitución de la ciudadanía como actor político. En Surco ensaya una reflexión social crítica de la dinámica política imperante que, si bien, no propone trasformaciones radicales de corte revolucionario, constituye un desafío el poder político instituido. Para entonces lo encontramos actuando en distintos escenarios conceptuales. Por una parte se compromete con una visión dinámica de la historia y, desarrollando el concepto de ciudadanía, visibiliza y concede protagonismo al mundo social en la práctica de la política. Pero, por otra, Monge Alfaro se siente atraído

6 Pero Monge Alfaro no asocia el nazismo con una crisis definitiva de Occidente; en su concepción, de esta crisis saldrán soluciones para un futuro mejor. «Hacia una conciencia histórica costarricense» Surco II, 22 (1942): 5-8 (5).

7 Romero, 72; y Eugenio Rodríguez Vega, Biografía de Costa Rica (San José: Editorial Costa Rica, 1981) 169 . 
por construcciones estructurales deterministas que coexistirán sin solución de continuidad en sus distintas interpretaciones.

El triunfo de las fuerzas opositoras en la Revolución de 1948, convierte a los integrantes de Surco en fuerza hegemónica en la conformación de la Segunda República. El Partido Liberación Nacional, fundado en 1951, se constituirá en la segunda mitad del siglo xx en rector de las políticas del país. Monge Alfaro y el resto de sus compañeros se constituirán en elementos claves en la construcción de la edificación política que dará forma al Estado y a la nación, la cual, paradójicamente, será heredera de vicios del pasado criticados en sus textos sobre las odiadas oligarquías pero invisibilizados en el mundo ideal del poder que sucede al calderonismo. Como rector de la Universidad de Costa Rica y profesor de su Escuela de Historia, las tesis de Monge Alfaro tendrán una amplia incidencia en la producción académica y en la visión de nación proyectada desde el Estado. Si bien en la década de 1940 Monge Alfaro persigue con su discurso contribuir a crear un nuevo proyecto de sociedad, en décadas posteriores, su discurso pierde el dinamismo inicial que encontraremos en las páginas de Surco inclinándose por la validación del presente. Cazanga y Reyes advierten la centralidad otorgada por Monge Alfaro a la historia y, en particular, en dicha publicación periódica ${ }^{8}$. Sin embargo, atribuyen esta característica a un autor supuestamente homogéneo, que mantiene la coherencia discursiva inicial durante el resto de su vida académica9 ${ }^{9}$. Ello no es así y difícilmente podría serlo.

\section{Ciudadanía y nación en Surco}

En 1941 Monge Alfaro proponía en Surco una noción innovadora y desafiante de la ciudadanía al concebirla no como ente pasivo, preconstituido, sino como producto de la historia. La ciudadanía, eje

\footnotetext{
8 Osvaldo Cazanga Moncada y Juan Reyes Meza, Carlos Monge Alfaro. El hombre y su tiempo (San José: Ediciones Guayacán, 1988).

9 Quesada y otros, 5.
} 
de la vida política, según nos dice Monge Alfaro asumiendo una posición que no deja de parecernos cercana a la de Friedrich Nietzsche, dota de «sentido y fuerza vital»a la nación ${ }^{10}$. Según Monge Alfaro, la historia tiene un «uso» histórico, no un simple producto de un análisis objetivo independiente de su tiempo; lo que Nietzsche llamaría «la verdad de la época»; la cultura es fuerza creativa, opuesta a un tiempo «monótono, vacío, carente de todo tipo de «acontecimientos» ${ }^{11}$, carencia que no deviene de la historia en si misma sino del tiempo presente; pero Monge Alfaro encuentra un anclaje moral en esa cultura al adjetivarla como «cívica» ${ }^{12}$. El dinamismo de la historia es colocado en la ciudadanía y ésta es producto de la educación formal y de la permanente formación cívica. Por ello que la participación política es característica inherente del ciudadano. Con Rodrigo Facio, considera a los partidos políticos terreno dilecto de construcción democrática ${ }^{13}$. Anquilosados grupúsculos clientelistas deben ser sustituidos por espacios horizontales de participación donde el interés colectivo sustituya al individual y la búsqueda del bien común a las negociaciones espúreas. La vitalidad, la energía de la nación deviene del mundo social que la compone que, en los textos estudiados de Surco, se define exclusivamente con la palabra «ciudadanía». Si en la etapa de mayor madurez de Antonio Gramsci, la ciudadanía es factor constitutivo del Estado, en el joven Monge Alfaro, el progreso de la vida política está en esa comunión propuesta entre Estado y comunidad nacional. No hay pruebas de que Monge Alfaro conociera los escritos de Gramsci; sin embargo, sorprende la cercanía entre ambos en lo que respecta a la construcción de lo que el estudioso de la política italiana llamaría hegemonía, ese consenso que constantemente se reconstituye a partir

10 Carlos Monge Alfaro, «Hacia una conciencia histórica costarricense» Surco I, 14 (1941): 8-10 (9).

11 Germán Cano, Germán, «Nietzsche y la poderosa fuera del presente. Una introducción a «Sobre la utilidad y el perjuicio de la historia para la vida» en Friedrich Nietzsche, Sobre la utilidad y el perjuicio de la historia para la vida [II Intempestiva] (Madrid: Biblioteca Nueva, 1999) 26.

12 Quesada y otros señalan la influencia de profesores alemanes en Carlos Monge Alfaro, 66; posiblemente a través de ellos conoció la obra de Nietzsche.

13 Carlos Monge Alfaro, «Hacia una conciencia histórica costarricense» Surco I, 15 (1941): 5-7(6). 
de los desafíos del mundo subalterno. En Monge Alfaro, la modernización de la política en Costa Rica demanda de una ciudadanía capaz de constituirse en el eje de la transformación política, de propiciar el avance, en el sentido gramsciano, del Estado y la nación ${ }^{14}$. En Gramsci la política es construida como un campo de fuerzas en el que constantemente se recrea el sistema hegemónico. En sus reflexiones teóricas sobre la ciudadanía Monge Alfaro lo concibe como un conjunto articulado capaz de cuestionar, negociar, replantear la dominación bajo el liderazgo de una intelectualidad representativa de sus intereses, liderazgo que naturalmente corresponde a los integrantes del «Centro para el estudio de los problemas nacionales». Pero esa vitalidad que le atribuye a la esfera política no es condición sine qua non de la ciudadanía. Es una construcción. La nación también puede adquirir el rostro de un estado fantasmal integrado por «ciudadanos vacíos interiormente» inaptos para la vida democrática ${ }^{15}$. Es precisamente ese Estado el que impera en su contemporaneidad. La política se ha convertido en teatro «vacío, hueco, sin alma» ${ }^{16}$. El teatro en este contexto representa la construcción intencional de discursos falsos, manipuladores. Ese «vacío» de la política es compartido por los dirigentes y sus bases. A un conglomerado social carente de «sentido de vida democrático» surge una dirigencia clientelista y corrupta. Monge Alfaro insiste en las páginas en la construcción de un proyecto de país que integre a la colectividad social, dotando la esfera política del «sentido vital» necesario para construir ciudadanía y nación ${ }^{17}$. La «nacionalidad» no es cualidad adquirida mediante recursos teleológicos, ni herencia de gloriosos antepasados. Es una construcción colectiva, «voluntad e iniciativa de todo un pueblo, primero en la conciencia, luego en las instituciones» ${ }^{18}$. La vitalidad de la nación permite trazar el horizonte de futuro. Resulta

14 Martin Carnoy, The State and Political Theory (Nueva Jersey: Princeton University Press, 1984) 65-88. 15 Monge Alfaro, Surco I, 15 (1941): 5-7 (5).

16 Monge Alfaro, «El liberalismo en Costa Rica». Surco IV, 43 (1944): 8-9 (9).

17 Monge Alfaro, «A propósito del 15 de setiembre», Surco Año I, 1 (1940): 3-4 (4).

18 Monge Alfaro, «La cátedra, el libro y el periódico: cinceladores de la nueva nacionalidad», Surco IV, 46 (1944): 6-7 (6). 
asombrosa la cercanía que nuestro autor muestra tener con el pensador marxista italiano, en cuanto a la centralidad otorgada a la cultura tanto en la construcción del poder como en las estrategias que le pueden desafiar. La sociedad civil aparece como construcción cultural con capacidad de superar la aquiescencia a las clases gobernantes, con capacidad de incidir y transformar las instituciones que la integran, a partir de su participación en la vida política.

\section{La historia en Surco}

La historia aparece en su obra inicial como factor clave de comprensión de la contemporaneidad. Debe constituirse en una narrativa al servicio del presente para la construcción del futuro. En 1934, Monge Alfaro regresa al país luego de sus estudios en Chile, trayendo consigo una visión hasta entonces desconocida de la historia. La renovación histórica que se ha dado en Francia, Monge Alfaro la adopta mediante la influencia que en la vida intelectual chilena tuviera Henri Beer, una de las figuras prominentes en la creación del grupo de historiadores que se constituyen alrededor de la revista $\mathrm{An}$ nales, fundada en $1929^{19}$. Beer promovió la interdisciplinariedad en la historia y bajo el influjo de autores como Augusto Comte, Herbert Spencer y Emile Durkheim, la naciente Escuela de los Annales, criticó la historia orientada a la narración de hechos, para promover una narrativa diacrónica dirigida a la interpretación del desenvolvimiento de las sociedades; es decir, una historia cuyo eje es la comprensión de las sociedades en aras de contribuir a aprehender los procesos contemporáneos ${ }^{20}$. En «Hacia una conciencia histórica costarricense», sugiere que la historia es la necesaria compañera del cambio.

19 Peter Burke, La revolución historiográfica francesa. La escuela de los Annales: 1929-1989 (Barcelona: Gedisa Editorial, 1990) 28.

20 Burke, 17. Sobre la influencia de la renovada corriente historiográfica francesa en Monge Alfaro, puede consultarse: Quesada y otros, 63-71. Iván Molina, refiriéndose a la influencia de Henri Beer sobre Monge Alfaro, señala que para éste no es la cantidad de detalles y datos lo intrínsecamente interesante, sino la fertilidad del hecho (10). 
Define conciencia histórica como «intuición de futuro» ${ }^{21}$. La historia, por tanto, es instrumento clave en la creación de proyectos de sociedad, su exploración ofrece las coordenadas del cambio. En Costa Rica la conciencia histórica, lejos de prevalecer, ha estado presente solo en personajes políticos excepcionales como José María Castro Madriz (1847-1849) y en una específica generación: la generación liberal de 1889, que condujo al país de una fase patriarcal, «fase primitiva» de la República, a la democracia ${ }^{22}$. En Surco Monge Alfaro se distancia de los intelectuales sacralizadores del poder en su posición crítica a la historia de la vida política del país. La ciudadanía no aparece como «dada» sino como actor vital, de una democracia que está por hacerse, por construirse. Señala que los liberales ortodoxos cumplieron «una misión histórica», pero no comprendieron «que la democracia es proceso, es perfeccionamiento» ${ }^{23}$. Aun cuando los derroteros de la historia aparecen, en este caso, marcados por «la necesidad», pues «tareas históricas» fundamentales trascienden el escenario de la política, requieren de ésta para ser llevadas a cabo.

\section{La ambivalencia entre la necesidad y la contingencia en la historia}

La tesis de la «democracia rural» fue planteada por Monge Alfaro en 1937. El sentido de igualdad de una supuesta sociedad colonial de pobreza generalizada, constituyó la esencia del labrador colonial, que se transmuta en espíritu ancestral del ser costarricense. La democracia rural se mantendrá como un eje fundamental de su producción histórica. Si bien la necesidad histórica tiene espacio en el Monge Alfaro de la década de 1940, la contingencia prevalece. En sus artículos de Surco solamente una colectividad social partícipe en la construcción de la política es capaz de llevar adelante la nación. En Costa Rica los promotores del liberalismo ortodoxo que, en su concepto, desvirtuó

21 Monge Alfaro, Surco I, 14 (1941): 8-10(8).

22 Monge Alfaro Surco I, 14 (1941): 8-10 (9).

23 Las cursivas son nuestras. Monge Alfaro, Surco II, 22 (1942): 5-8 (6). 
los ideales de la Revolución Francesa anteponiendo los egoístas intereses del capital al desarrollo integral del ser humano, impidieron el desarrollo de la cultura democrática. Ésta no se manifiesta exclusivamente en momentos específicos de la vida política, es parte integral de la subjetividad, del «sentido de la vida» ${ }^{24}$, a que el autor refiere y que se acerca a lo que Gramsci denomina «sentido común.»

Ese labriego del siglo xviii que en años posteriores será representado por Monge Alfaro como la esencia misma de la democracia en Costa Rica, no fue visto por él con la misma empatía en sus escritos de la década de 1940. Durante el siglo xix, el costarricense «continuó siendo individualista, sin ideales, sin fuerza social» ${ }^{25}$. Concibió a los herederos del labriego sencillo como «individualistas, rudos e incultos ${ }^{26}$, para quienes la idea de la participación cívica era demasiado abstracta para su comprensión. Sin embargo, para entonces Monge Alfaro, contradictoriamente, se moviliza con diferentes énfasis en sus escritos, entre la construcción de lo político y la necesidad histórica. Si bien visualiza al labriego como ser esencialmente igualitario, al situar la dimensión política en el terreno delacontingencia, éste aparece como sujeto poco apto para la vida democrática pues, frente a su individualismo, afirma Monge Alfaro, «¿qué sentido tendrían para ellos las instituciones democráticas que precisamente dependen de fuerzas colectivas?» ${ }^{27}$. En esta herencia ancestral radica el problema de la vida política. Monge Alfaro también convierte al ancestral labriego en el símbolo de la libertad y, contradictoriamente, ofrece una visión del pasado donde los valores que él representa han tenido «fuerza vital de eterna presencia» ${ }^{28}$.

Lejos de idealizar el pasado, retrata un país que, hasta el presente, ha estado sometido al dominio de oligarquías. En las páginas de Surco predomina un ideal de nación fundamentado en la participación

24 Monge Alfaro, «Hacia una conciencia histórica costarricense», Surco II, 23 (1942): 4-6(6).

25 Monge Alfaro, «Hacia una conciencia histórica costarricense», Surco II, 24 (1942): 5-8(7).

26 Monge Alfaro, «Hacia una conciencia histórica costarricense». Surco II, 26 (1942): 7-9(5).

27 Monge Alfaro, Surco II, 26 (1942): 7-9 (7).

28 Monge Alfaro, «El liberalismo en Costa Rica» Surco IV, 45 (1944): 7-9 (8). 
ciudadana pues «la democracia es medio y no fin de la vida ${ }^{29}$. Lo político, lo contingente, obnubila las escasas enunciaciones en las que los determinismos identitarios se hacen manifiestos. Autores como Alexander Jiménez critican a la idealización que Monge Alfaro realiza de la historia de Costa Rica a partir de la supuesta igualdad imperante en el mundo rural. Aquí, en nuestra opinión, nos proponemos mostrar que su visión de la historia pasa por transformaciones sustantivas en el tiempo y en la década de 1940 el autor ofreció una versión de la historia mucho más rica y compleja y si bien ésta no se encontró totalmente desligada de perspectivas «metafísicas» (apropiándonos de un concepto ensayado por Jiménez) la desigualdad social y la prepotencia política prevalecieron en su análisis ensombreciendo esa herencia democrática ancestral del labrador ${ }^{30}$.

Su discurso utiliza la historia para culminar en la crítica de la política contemporánea ${ }^{31}$. La oligarquía en el siglo xix careció de «pensamiento director ${ }^{32}$. Esta referencia crítica tiene como objetivo el presente: Monge Alfaro establece un parangón entre la oligarquía del siglo xix y los grupos que para entonces ostentan el poder. José María Castro luchó sin éxito en favor de la democracia, pues el conjunto social compuesto de hombres ricos y pobres, no estaba preparado para asumir los retos de la democracia. La tarea urgente del presente, afirma, consiste en «limpiar la democracia de sombras maléficas, en otras palabras, de la oligarquía civil» ${ }^{33}$.

29 Monge Alfaro, Surco I, 1 (1940): 3-4 (4). En esta cita Monge Alfaro coincide con uno de los más importantes estudiosos de los procesos políticos de la contemporaneidad. Norbert Lechner entiende por consenso lo que Monge Alfaro llama democracia. Para el primero, «la organización de la voluntad colectiva no puede apoyarse en un consenso y, sin embargo, tampoco puede prescindir de él» (Norbert Lechner, «El consenso como estrategia y como utopía», Zona Abierta II, 29 (1983): 1-29). Es decir, si el consenso se convierte en fin, se impone la tiranía. Monge Alfaro comparte la misma idea cuando adjudica a la democracia (léase práctica democrática) carácter de ensayo permanente, de negociación siempre abierta.

30 Alexander Jiménez Matarrita, El imposible país de los filósofos. El discurso filosófico y la invención de Costa Rica (San José: Editorial de la Universidad de Costa Rica, 2005) 246-252.

31 Quesada y otros, 97-98.

32 Monge Alfaro, Surco II, 12 (1942): 6.

33 Monge Alfaro, Surco II, 12 (1942): 5-6. 
Sin embargo, para entonces Monge Alfaro contradictoriamente se moviliza, con diferentes énfasis en sus escritos, entre lo político como constructo social y la necesidad histórica. En su Geografía social y humana de Costa Rica, la geografía es factor determinante de la subjetividad. El conservadurismo y el individualismo que atribuye a los costarricenses deviene de un ser ancestral que se forjó en el aislamiento en las regiones altas del país ${ }^{34}$. A inicios del siglo $\mathrm{xx}$, en la invención de conceptos como el ser indoamericano o latinoamericano se ensayó recurrentemente una narrativa en la que un «espíritu» de la raza, procedente de un pasado ancestral, determinado por factores históricos reiterativos o bien por condicionamientos geográficos, se constituyó en forjador de una identidad trascendente de la historia, imponiendo su marca en cada integrante de ese mundo social. Monge Alfaro es heredero de una tradición latinoamericana que enlazó el determinismo cultural y el geográfico. Ese abstracto ser latinoamericano que se remonta a través de los siglos, no constituyó necesariamente un ser ontológico «ideal». En las primeras décadas del siglo xx autores como Carlos Octavio Bunge se ocuparon de señalar las negativas herencias ancestrales de estos pueblos para contraponerlas con aquellos que habían alcanzado la cima del progreso $^{35}$. Monge Alfaro también creó una herencia ancestral que

34 Según un autor de Surco que se presenta como J. R., esta obra de Monge Alfaro hace hincapié en la formación de un ser social particular en el mundo latinoamericano, entelequia de la igualdad. J. R., «Leemos Geografía social y humana de Costa Rica. Libro del Prof. Carlos Monge A.», Surco II, 25 (1942): 14-15.

35 Carlos Octavio Bunge, Nuestra América: ensayo de psicología social, 6a ed. (Buenos Aires: Vaccaro, 1918); anteriormente había publicado «Nuestra América», Pandemonium III, 37 (1904): 6-8. En 1902 en la revista cultural Pandemonium, J. A. R. se había referido «atavismo de raza» que ha limitado el «desenvolvimiento» de los habitantes de las antiguas colonias españolas, para explicar las distancias entre América Latina y el mundo sajón (J. A. R. «Atavismo de raza», Pandemonium (nov. de 1902): 113-116. Esta expresión sugiere una herencia ancestral que trasciende la voluntad individual posesionándose de las subjetividades de la región independientemente de sus características étnicas o regionales o de clase. Según J. A. R., hay un defecto originario en ese supuesto «ser latinoamericano» que se reproduce en sucesivas generaciones, defecto que no reside en características físicas sino en el carácter y el temperamento. El intelectual argentino Octavio Bunge en la década de 1910 sostiene que la «raza española» se caracteriza por su arrogancia, cuya génesis «se pierde en la noche de la prehistoria porque se haya más que en la raza, en la geografía». (Bunge, 1918, citado por Martin 
mostraba las flaquezas arrastradas por siglos por ese sujeto representativo de la colectividad. Pero su narrativa no se ocuparía de delinear al ser latinoamericano; fijaría los límites culturales entre Costa Rica y el resto de América Latina. Si bien el espíritu del labrador surge de una pequeña porción del territorio costarricense, la Meseta Central, cubre la geografía nacional, estableciendo fronteras profundas entre este país y sus vecinos.

En suma, Monge Alfaro ofrece en Surco una historia orientada a la crítica del presente y destinada a constituirse en el basamento de un nuevo proyecto nacional. Ante la urgencia del cambio y la necesidad de contar con el apoyo masivo de la población para que esta nueva generación pueda ocupar el poder, Monge Alfaro encuentra recursos retóricos de envergadura en la construcción de una visión de la historia que sancione el presente y que, a la vez, integre a la colectividad social como partícipe responsable de su historia. Sin embargo, las ambivalencias de sus propuestas iniciales se convertirán en ejes rectores de su discursividad en décadas posteriores. Historia de Costa Rica cuya versión inicial, según Quesada y otros circuló mimeografiada en 19396, alcanza diecisiete ediciones hasta 1982. Sin embargo, diferencias sutiles darán fuerza al abstracto personaje del labriego sencillo, estrategia discursiva que le permite trazar con mayor firmeza una concepción elitista del cambio en la sociedad.

\footnotetext{
S. Stabb, América Latina. En busca de una identidad (Venezuela: Monte Ávila, 1969) 28-29. Según Bunge, aun cuando se transformen los factores geográficos e históricos que dieron lugar a características fundamentales de las razas, estas persisten heredándose en sus descendientes y, cuando las razas se mezclan, los rasgos degenerados de ambas razas se imponen en el vástago producto de la hibridez (Stabb, 29). Por otro lado, Alcides Arguedas define al indio aymara como un grupo humano cuya identidad se forja en la aridez de Los Andes, geografía poco amable que lo convierte en «reacio, malicioso, egoísta, cruel, vengativo y celosamente malévolo» (Arguedas, citado por Stabb, 36); cfr. Alcides Arguedas, Pueblo enfermo, 3a. ed. (Santiago de Chile: Ercilla, (1909) 1937). En estos autores el determinismo actúa como una condena de la herencia indígena y latina por una supuesta inferioridad intrínseca (Hale, citado por Stabb, 32); cfr. Charles Hale, «Ideas políticas y sociales en América Latina, 1870-1930», en Leslie Bethell, ed. América Latina. Cultura y sociedad. 1830-1930 (Barcelona: Editorial Crítica, 2000) 28-29.
}

Quesada y otros, 99. 


\section{Historia de Costa Rica: un giro en su narrativa histórica}

En Historia de Costa Rica ${ }^{37}$, Monge Alfaro, lejos de utilizar la historia para justificar la crítica a quienes gobiernan, legitima un presente que se extiende hacia un futuro de progreso y bienestar. El ciudadano, otrora convocado a participar activamente en la vida política, se fosiliza en una identidad ideal, acabada pues se trata de «Ciudadanos orgullosos de su patria... arquitectos de un pueblo que lo llevan auténticamente en el alma» ${ }^{38}$. Una relación sinecdóquica entre el labriego sencillo y el «pueblo», sujeto político homogéneo impide el escape de espacios identitarios de ese núcleo central de la subjetividad pues el labrador es «figura central de nuestra historia política, social, económica y cultural...» ${ }^{39}$.

En este texto el concepto pueblo actúa como sinónimo de ciudadanía pero ello no significa que éste contenga las características políticas de la ciudadanía, cuidadosamente construidas en las páginas de Surco. Lo que ha ocurrido es que un idealizado y abstracto concepto de pueblo actúa contradictoriamente como sinónimo del concepto «ciudadanía» una vez éste ha sido vaciado del contenido previo, en el cual se buscaba representar una comunidad política capaz de delinear su destino histórico. El labrador es la antítesis del ciudadano pues, por antonomasia, es apolítico. Ser de horizontes restringidos, autónomo por la perdurable experiencia de aislamiento, experiencia que, en forma ambivalente, lo aleja de la vida política, pero lo dota, según la edición de 1982, del sentido de libertad. He aquí una de las mayores contradicciones del discurso de Monge Alfaro. En sus reflexiones sobre la ciudadanía y la nación la vitalidad de la democracia se encuentra en su práctica política, imprescindible

37 Nos basamos en las siguientes líneas en la edición revisada por el autor que fue publicada en 1982, la cual corresponde a la 17a edición y establecemos algunas comparaciones entre ésta y la 5a edición publicada en 1955.

38 Carlos Monge Alfaro, Historia de Costa Rica (San José: Talleres Gráficos de Trejos hermanos SUCS, 1982) 16.

39 Monge Alfaro (1982) 160. 
para superar el caudillismo y conducir al pueblo hacia un orden político y social superior. En cambio, el autor en estas páginas de Historia de Costa Rica, lejos de convocar a superar ese ser pasivo, individualista, llama a sus lectores a considerar esa figura como «grandiosa, digna de reverencia y de profundo amor, porque dio a Costa Rica las bases fundamentales de lo que andando el tiempo será la democracia rural. En el alma de ese labrador se gestaba una gran historia de la democracia» ${ }^{40}$.

La relación entre el labrador colonial y la «vocación democrática» del pueblo de Costa Rica aparece en los primeros trabajos de Monge Alfaro, aunque está representado con rasgos identitarios poco amables. El proceso de transformación de la figura del labriego, se aprecia en las distintas temporalidades de las ediciones de Historia de CostaRica. Encontramos una diferencia sustantiva entreesa figura idealizada que ofrece la última edición de su obra, y aquella que nos ofrece en versiones más antiguas. En la edición de 1955, su análisis de esa figura que moldea el ser social costarricense, es más ambigua. Cuando en el siglo xix se forjaron las instituciones republicanas, aparecióel rostronegativodel individualismo, causa, aun en la actualidad «de los males y desventuras nacionales»; refiere a «esa indiferencia y sordidez por los problemas sociales; ese espíritu de indisciplina; esa actitud disgregadora que brota apenas se trata de animar empresas de orden social $»^{41}$. Lejos de constituir un sujeto esencialmente dispuesto para las prácticas políticas, dificultó la tarea formadora de ciudadanos a los gobernantes del siglo xix. Pero, contradictoriamente, ya en esta temprana edición Monge Alfaro atribuye a este labrador el fundamento de la democracia costarricense. Es portador del sentimiento de igualdad, aunque en versiones posteriores, más bien lo representará como portador del sentimiento de libertad. ¿Será acaso que para finales de la década de 1970 el ideal de igualdad resultaba comprometedor para un modelo de sociedad que, si bien promovió el ascenso de

40 Monge Alfaro (1982) 160.

41 Carlos Monge Alfaro, Historia de Costa Rica (San José: Librería Las Américas, 1995) 127. 
sectores subalternos a las clases medias, no tuvo la capacidad de evitar el incremento de la brecha social?

En la narrativa de Historia de Costa Rica, si bien «el pueblo» - es decir, los costarricenses que no pertenecen a la cúpula - tiene una posición política predeterminada, la elite económica y política, en cambio, está compuesta de actores independientes de ese ser esencial costarricense. Braulio Carrillo apoyado por hombres poderosos se constituyó en dictador José María Castro primer presidente de Costa Rica (1847-49) abanderado de la democracia fue derrotado por el ejército y políticos influyentes. En su narrativa en el resto del siglo xix, las pocas voces promotoras de la democracia son opacadas por gobernantes que, lejos de apoyarse en el pueblo, lo hacen en la institución militar. Juan Rafael Mora quien escribió una de las «páginas más brillantes de la historia americana»; «tenía defectos que lo llevaron a ejercer el mando a veces con mano de hierro» ${ }^{42}$. En 1852 disolvió el congreso e hizo gobierno de círculo beneficiando a sus amigos y parientes y después de diez años de tener el poder no comprendió que le había llegado la hora de marcharse.

En versiones previas de la historia de Costa Rica, el comportamiento elitista y antidemocrático de los gobernantes está presente y claramente integrado a su propuesta discursiva, en la que subraya el predominio de la oligarquía en la vida independiente y la necesidad de crear una ciudadanía activa, vital, que confronte a dicho grupúsculo en el poder. Pero en Historia de Costa Rica, Monge Alfaro no da respuesta a una contradicción que lo lleva a conformar una compleja panorámica de hombres públicos, cada uno de ellos con rasgos personales y estilos de gobiernos particulares, la mayoría de ellos, por lo menos en el siglo xix, poco propicios a la promoción de una construcción democrática del poder.

Su relato rompe abruptamente con la idealización de la estructura agraria costarricense. A raíz de la expansión de la agricultura 
comercial, sustanciales transformaciones sociales ocurren. Sostiene el autor que en las zonas más dinámicas y de mayor concentración poblacional, el labrador ya no es un personaje central pues, gracias al fortalecimiento de la oligarquía, «la pequeña propiedad casi no existe en las zonas cafetaleras; hay que irla a buscar a las regiones dedicadas al cultivo del arroz, maíz, frijoles, papas, etc.» ${ }^{43}$. Esa figura social que dio origen al costarricense, convertida en marginal, sigue constituyendo el eje básico que orienta el imaginario cultural y determina el horizonte subjetivo. El «pueblo» es un sujeto político homogéneo y predeterminado por una historia que, en su relato, cuanto más se acerca al siglo xx, más se distancia de los fundamentos que le dieron forma. Sin embargo, en la visión de desarrollo lineal y progresivo de la historia que el autor ofrece, el pueblo va adquiriendo mayor visibilidad conforme se avanza en el tiempo. Aparece ese pueblo luchando por hacer respetar su voto, cuando en 1889 Bernardo Soto desconoce el triunfo de José Joaquín Rodríguez. Pero tampoco el pueblo parece actuar coherentemente con la identidad que el autor le atribuye. El dictador Tinoco alcanza poder con su apoyo. Sin embargo, Monge Alfaro no explica cómo la esencial voluntad democrática es contingentemente abandonada en el proceso histórico.

A finales del siglo xix el país asiste a la transición de la república oligárquica a la liberal. Los personajes de poder económico son sustituidos por los promotores del intelecto. Con Cleto González Víquez (1906-1910) los partidos en esos años ya no eran círculos de amigos, constituían grandes agrupaciones «en las cualesmilitaban vastos sectores del pueblo. Campesinos y obreros intervenían en la política con el mismo derecho que los sectoreseconómicos poderosos» (255-256) En este gobierno «elciudadanoCostarricense conquista - noporlafuerza sino por la evolución misma de las instituciones, ideas y costumbreslos más preciados derechos democráticos» (256)Un procesoevolutivo que es presentado porel autor en forma abstracta, conducea laigualdad

43 Monge Alfaro (1982) 226. 
en el terreno político. Ésta, para entonces garantiza a esa unidad denominada pueblo, aunque no sin retrocesos circunstanciales como la dictadura tinoquista, un futuro donde el progreso hacia la afirmación de la democracia predominará sobre los «tropiezos» ocasionales.

A finales de la década de 1970 Monge Alfaro publica, con Francisco Rivas Ríos, La educación: fragua de nuestra democracia. En esta versión de la sociedad costarricense, una historia sin contradicciones actúa como escenario necesario de un país en cuyo presente se ha cristalizado la vida política requerida para hacer avanzar el país hacia el progreso material y cultural. Los «ciudadanos» desaparecen por completo como actores de la historia y aquellos gobiernos oligarcas del siglo xix y de sus años de militancia en las filas opositoras, que ocuparon un lugar de privilegio en sus páginas, se desdibujan en una sociedad donde «desde que se recibió la noticia de la independencia la característica fundamental... fue la vida civil» ${ }^{44}$. El civismo que a través de su obra atribuye al gobernante José María Castro, otrora una excepción en la vida política del país, en $L a$ educación, es parte de una historia de continuidad ininterrumpida ${ }^{45}$. Si en Surco Monge Alfaro problematiza la relación entre la ruralidad y la dimensión política, en Historia de Costa Rica convierte al «espíritu» de un sencillo labriego en extinción en el sustento de la libertad y la democracia (con énfasis variables según la época de la edición) que existe en esencia pero también en contradicción con una vida política donde oligarcas y tiranos, con alguna regularidad, encuentran un buen espacio para asentarse, en La educación, en cambio, Monge Alfaro y Rivas cómodamente establecen una relación sinecdóquica entre la supuesta pobreza colonial y la conformación de un país democrático con vocación civilista y orientado desde sus inicios al fomento de la educación ${ }^{46}$.

44 Carlos Monge Alfaro y Francisco Rivas Ríos, La educación: fragua de nuestra democracia (San José: Editorial Universidad de Costa Rica, 1984) 6.

45 Monge Alfaro (1984) 11.

46 Monge Alfaro (1984) 18. 


\section{Conclusiones}

En la obra de Carlos Monge Alfaro hay perspectivas distintas, incluso contradictorias, de la construcción de la dinámica política e histórica. Ya en la década de 1930, diversas influencias permean su trabajo. Para entonces, el determinismo geográfico e histórico acompañado de la constitución de subjetividades esenciales, ha sido ensayado por autores diversos que buscan comprender pero fundamentalmente crear una identidad latinoamericana. La experiencia chilena le abre posibilidades de ingresar en la revolución historiográfica que tiene lugar para entonces en Francia y, a la vez, de explorar novedosas propuestas de construcción del mundo político, que podríamos decir, estarían en armonía con las reflexiones que estudiosos del tema han venido ensayando en la actualidad sobre el papel de la ciudadanía y el estado en la dinámica social.

Pero Monge Alfaro es un autor con diversos rostros. Su cambiante postura se encuentra en relación con su posición como «intelectual orgánico» En los primeros años de la década de 1940, como uno de los actores protagónicos en la oposición al flamante calderonismo, encontró en la idea de revitalización de la ciudadanía y en la construcción de una historia destinada a colocar en perspectiva crítica el presente, un fértil terreno para convertir su enunciación en herramienta al servicio de la política. En sus últimos años, Monge Alfaro mostró su congruencia con la clase política en el poder, enfatizando en la idealización del labrador colonial, abstracto personaje, en declive como sujeto histórico desde inicios del siglo xix, pero dotado de una fuerza simbólica que trasciende el tiempo, penetrando y petrificando al denominado costarricense. También contribuyó a crear una historia contemporánea armoniosa al representar a los vencedores de la Revolución del 48 como un grupo homogéneo, comprometido con el bienestar de la patria y dispuesto a continuar el buen camino trazado por sus predecesores pero también a renunciar a sus malas prácticas. El país había alcanzado el ideal democrático. 
El «labrador de espíritu libre» pero apolítico aparecería entonces en armonía con una clase política que de antemano conoce cuál es el rumbo a seguir.

Sin embargo, no es posible atribuir los cambios operados en el discurso de Monge Alfaro simplemente a las urgencias políticas a las que responde. Mientras reflexionó sobre el ciudadano como constructor de la historia, acudió a la geografía en busca de la inmanencia del ser costarricense. En tanto desarrolló una rica discursividad en torno a la vitalidad de la participación social en el cambio histórico, presentó un pasado en el que los actores políticos, caudillezcos o liberales, constructores de civilidad o de tiranía, actuaron con independencia del mundo social. Por supuesto, con esto no negamos que en algunos momentos de la historia «el pueblo» se haga presente en las páginas de Monge Alfaro. Las luchas por la defensa del sufragio que tuvieron lugar en 1889 y que en contra de la voluntad del grupo gobernante llevaron a Rodríguez al poder, resultan una excepción. Pero lo que queremos enfatizar es que en su discursividad, la vida política pudo desarrollarse tomando diversos rumbos sin más intervención que la de los grandes personajes.

Con este estudio no se ha buscado «desmitificar» una figura ya emblemática en la historia nacional, labor que ha sido emprendida por historiadores que en las décadas de 1970 y 1980 mostraron que el mundo colonial tardío distó de ser el paradigma de la igualdad y la libertad. Monge Alfaro no es un autor monolítico y su discursividad ha respondido a sus inquietudes como colaborador en la construcción de la nación costarricense, como estudioso de las tendencias renovadoras de la historia y de las ciencias sociales y, finalmente, como intelectual orgánico, inicialmente ubicado en la oposición, pero durante la mayor parte de su quehacer político en el poder. Estas distintas «posiciones de sujeto» se combinan para producir narrativas ambivalentes en sus concepciones analíticas, que permearon su discursividad en torno a la sociedad costarricense. 